\title{
IMPROVING OF DELIVERY RELIABILITY AND THROUGHPUT USING PRODUCTION PLANNING WITH CONWIP ASPECTS
}

\author{
DURANIK, T[omas]; RUZBARSKY, J[uraj] \& STOPPER, M[arkus]
}

\begin{abstract}
Production systems such as the CONWIP (constant work-in-process) pull production system have been widely studied by researchers to date. The CONWIP pull production system is an alternative to pure push and pure pull production systems that lowers and controls inventory levels (throughput) and reduces production lead time and delivery reliability. In this article a CONWIP pull production system was simulated in place of a current push production system to compare these systems via a CONWIP planning game with set up parameters of production. The proposal was to reduce the total WIP and achieve inventory (throughput) and lead time (delivery reliability) to minimum values. After that it was recorded and displayed in an excel sheet. A future state was made for real production of plastic components and the setup of the two indicators with CONWIP pull production system which can the company greatly help to by more competitive on the market.

Keywords: improving delivery reliability, throughput, production planning system, CONWIP, improved planing
\end{abstract}

\section{INTRODUCTION}

What is a problem almost every manufacturing enterprise? Let us not account sales, because it is made up of present state of crisis in the economy. But it is a manufacturing process in the company. That is the important process that consists of several sub-processes that are in tune and work to complement with each other, and which it is necessary to plan and control. When something changes in production it is necessary that all production process must accommodate the change.

Otherwise occur 4 main problems, namely:

1. Customer's failure to deliver the product at the right time

2. Incomplete removal of resources

3. Large inventory in stock

4. Interim extension of time

All these problems in production can be avoided by action called as PPS (Planning and production control systems), which in this article are solved.

\section{PROBLEM STATEMENT}

Assessing the actual situation in the company shows low reliability and smal throughput in production. As long as these problems are not solved, resources have to be increased, the usage of potential falls down, this means redundancies, low delivery reliability will leads to lost customers and longer throughtput time will make the production more expensive. Dramaticaly ends, but wery trustworthy if the production will no work effective and responsibly and will not give a great focus on production planning.

\section{GOAL AND APPLICATION}

Goal of this article is to present the reader in the easiest way the planning and control systems and production processes. Describe a hybrid push-pull CONWIP system his comparison with other planning systems on the example of planning and present implementation of CONWIP system to medium sized manufacturing enterprise engaged in the manufacture of products from thermosets.

\section{PRODUCTION PLANNING AND CONTROL SYSTEMS (PPC)}

Production planning without production control is like a bank without a bank manager, planning initiates action while control is an adjusting process, providing corrective measures for planned development. Production control regulates and stimulates the orderly how of materials in the manufacturing process from the beginning to the end. [3]

Production planning systems (PPS) are a specialized form of decision support system (DSS). There are over 100 commercial systems available. The purpose of a PPS is to take manufacturing requirements, match them with a model of the factory or the supply chain and, using various algorithms and technology, and craft a work sequence either automatically or with manual intervention. [7]

Production planning may be defined as the technique of foreseeing every step in a long series of separate operations, each step to be taken at the right time and in the right place and each operation to be performed in maximum efficiency. It helps entrepreneur to work out the quantity of material manpower, machine and money requires for producing predetermined level of output in given period of time. [8]

PPS process consists of [8]:

1. Routing

2. Scheduling

3. Loading

\subsection{Routing}

Under this, the operations, their path and sequence are established. To perform these operations the proper 
class of machines and personnel required are also worked out. The main aim of routing is to determine the best and cheapest sequence of operations and to ensure that this sequence is strictly followed. In small enterprises, this job is usually done by entrepreneur himself in a rather adhoc manner. Routing procedure involves following different activities. [8]

1. An analysis of the article to determine what to make and what to buy.

2. To determine the quality and type of material

3. Determining the manufacturing operations and their sequence.

4. A determination of lot sizes

5. Determination of scrap factors

6. An analysis of cost of the article

7. Organization of production control forms

\subsection{Scheduling}

It means working out of time that should be required to perform each operation and also the time necessary to perform the entire series as routed, making allowances for all factors concerned. It mainly concerns with time element and priorities of a job.[7]

\subsection{Loading}

The next step is the execution of the schedule plan as per the route chalked out it includes the assignment of the work to the operators at their machines or work places. So loading determines who will do the work as routing determines where and scheduling determines when it shall be done. Gantt Charts are most commonly used in small industries in order to determine the existing load and also to foresee how fast a job can be done. The usefulness of their technique lies in the fact that they compare what has been done and what ought to have been done.

Most of a small scale enterprise fail due to nonadherence to delivery schedules therefore they can be successful if they have ability to meet delivery order in time which no doubt depends upon production of quality goods in right time. It makes all the more important for entrepreneur to judge ahead of time what should be done, where and when thus to leave nothing to chance once the work has begun.[7]

\subsection{PPS Methods}

For each production, it is necessary to know which kind of method of the planning system is the right one. The PPS methods is pushing (MRP), pulling (kanban) or hybrid (KONWIP).

\section{PUSH SYSTEM}

The material is supplied to the individual workplaces according to a predetermined schedule, respectively. plan, regardless of its actual need instant, ie material is printed, an effort to exploit the maximum production capacity for work so may create unnecessary and accumulate reserves. Such planning is MRP (I,II) system. [3]

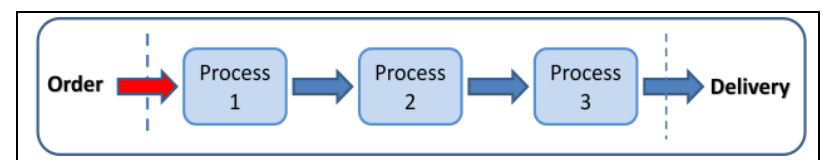

Fig. 1. Way of how FUSH system works

\section{PULL SYSTEM}

The material is supplied to individual workplaces based on need the instant, the material is pulled, it is processed immediately, is not stored, and therefore does not supply (such as KANBAN system) [3]

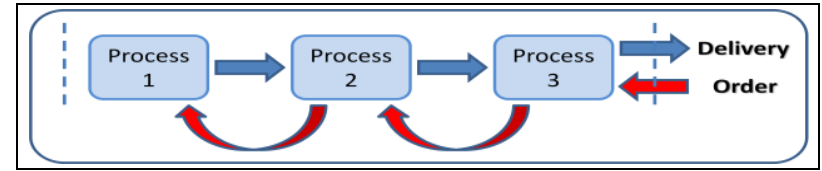

Fig. 2. Way of how PULL system works

\section{HYBRID SYSTEM}

The system uses the principle of pull and push to eliminate bottlenecks. Under "bottleneck" refers the weakest link of company, this area which in the situation of any particular load will by first causing difficultys and without removing it is impossible to grow. It may take the form of a concrete example of the production machine, improper organization of the business, inappropriate supply chain, etc... (for example CONWIP system) [1]

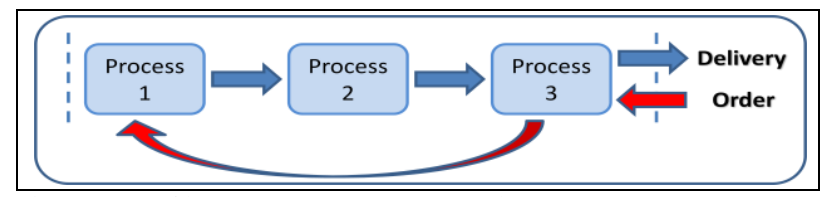

Fig. 3. Way of how HYBRIDE system works

\section{CONWIP}

CONWIP (Constant Work In Process) combines the advantages of kanban (shorter lead times and reduced inventory), but is applicable to a wider range of production systems. CONWIP is a generalization of the principle of kanban. The card is inserted into the container at the entrance to the production system and released at the output of the production system. [4]

While kanban system checked each procedural step separately, CONWIP defined using signals / card maximum inventory level in the so-called "Loop". After stocks run out at the end "loop" or card. Signal flows at the beginning and gives a signal to the pressure for further production. This "Loop" is also called a "ROP" (Reorder point). In the KANBAN system, this it is not possible, because the KANBAN system checks each operation separately. In some cases, particularly in complex manufacturing systems, where is large number of processes shared for many different types of productio, leads CONWIP production to lower total stock in the system than the KANBAN system. [4]

CONWIP system uses a single global system for inventory control cards anywhere in the flow. Material enters the CONWIP system only when the requirement arises to which is assigned signal card. The same card authorizes the movement of stocks across the stream to the final destination. When the final product leaves the 
process, the card is returned back to the beginning of the loop and the outlet stream to another material.

Under the term "raw material" we thing, work in progress from the previous processes, contracts, orders, information, that any entity to which it is happening controlled transformation process. An important aspect of CONWIP system is that the control does not happen on every separate process steps. This is a control process for simplified the management and easier to control as a whole unit, as compared to competitive systems MRP, ERP, or also kanban system. Moreover thanks to defined number of cards in the system is clearly been defined "Maximum stock level". System how CONWIP works is shown in Fig. 4 [4]

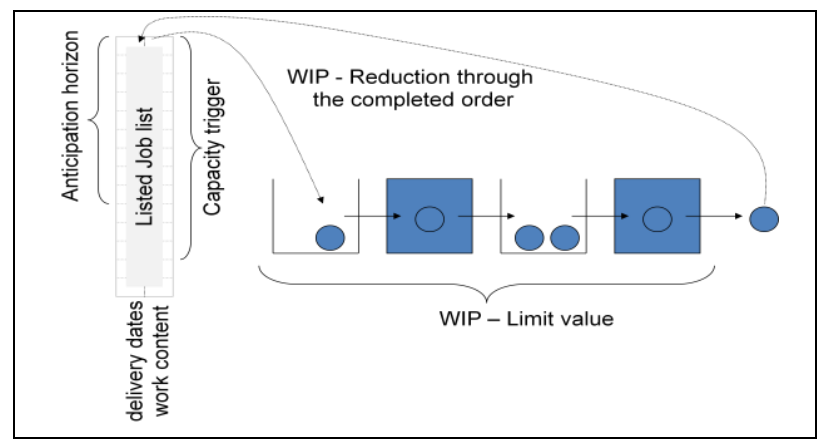

Fig. 4. Way of how CONWIP works [4]

\section{IMPROVING OF RELIABILITY AND THROUGHPUT WITH CONWIP}

Improving the reliability and throughput using CONWIP planning system lies in the fact that in to the production processes are manufacturing orders pushed, but only to the extent that the production volume reached its maximum. After the release of the finished order, can by pushed another commands in to theproduction. New order can by push in to production not only when ther is enought space, but also after a signal, or after crossing a minimal state level of stock. We simulate the 3 methods of production planning: MRP, KANBAN and CONWIP. Simulated production line consisted of 6 stations: material preparation, coating, painting, assembly, finishing station and finished goods stock. In the simulated game with MRP production planning, we got the results shown in Tab. 1.

\begin{tabular}{|c|c|c|c|}
\hline mrp_1 & $\begin{array}{l}\text { ㅇ } \\
\text { cे }\end{array}$ & 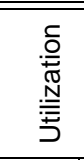 & 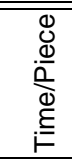 \\
\hline Stock & 53,9 & $47 \%$ & 32,5 \\
\hline WIP & 42,8 & & \\
\hline Finished goods & 11,0 & & \\
\hline 5_Finishing & 14,3 & $63 \%$ & 7,4 \\
\hline 4_Assembly & 6,9 & $29 \%$ & 4,7 \\
\hline 3_Paintwork & 6,7 & $43 \%$ & 6,3 \\
\hline 2_Surface prepareing & 10,8 & $55 \%$ & 7,4 \\
\hline 1_Cutting & 4,1 & $46 \%$ & 6,7 \\
\hline Delivery reliability & & $81 \%$ & \\
\hline
\end{tabular}

Tab. 1. First MRP result table

At MRP planning we are look at three parameters and they are the transition plan, the batch size and the security status of stock. In our case, we did not have the parameters of the transition plan and safety stock. It was set up just a batch size of 100pcs and length of play / production which was 12 minutes. As the table show out after manufacture our state of stock was at 53.9 pcs, utlilization $47 \%$ and time spent on one product was 32.5 seconds. The worst record in the table is order delivery reliability to customer. Reliability remained only on $81 \%$ of all orders. To reduce inventory and increase reliability it is need to change parameters in planning with MRP. We have changed the batchsize in half. Measured data from the second round are reported in Tab. 2.

\begin{tabular}{|c|c|c|c|}
\hline mrp_2 & $\begin{array}{l}\text { ü } \\
\stackrel{0}{i n}\end{array}$ & 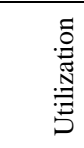 & $\frac{\mathscr{U}}{\stackrel{\mathscr{Z}}{\tilde{Q}}}$ \\
\hline Stock & 25,3 & $45 \%$ & 31,0 \\
\hline WIP & 19,7 & & \\
\hline Finished goods & 5,5 & & \\
\hline 5_Endfertigung & 5,1 & $44 \%$ & 6,2 \\
\hline 4_Baugruppenfert. & 3,7 & $36 \%$ & 4,8 \\
\hline 3_Lackierung & 4,7 & $51 \%$ & 7,1 \\
\hline 2_Surface prepareing & 4,0 & $42 \%$ & 5,9 \\
\hline 1_Cutting & 2,3 & $48 \%$ & 7,0 \\
\hline Delivery reliability & & $100 \%$ & \\
\hline
\end{tabular}

Tab. 2. Secod MRP result table

As in Tab. 2 spit out, after manufacture our state of stock stood at $25.3 \mathrm{pcs}$, the utilization is $45 \%$ and time spent on one product is 31 seconds. Visible change was observed in the data inventories and reliability of order fulfillment. The stock is on 25.3 pcs and reliability at $100 \%$. This record has shown us what can do a batchsize variation in production. The pull system is based on production kanban cards and also they are the main parameters of this system. Number of kanban containers and number of products per container (batchsize). The results of the pull planning system are shown in Tab. 3 .

As in Tab. 3 spit out, after manufacture our stock stood at 25.2 pcs, utilization at $52 \%$ and time spent on one product was 36.4 seconds. Compared to observed data of inventory with push system is roughly unchanged, but unlike the delivery reliability has deteriorated on $81 \%$. Deployment of Kanban containers was according to the balance and not by orders.

\begin{tabular}{|c|c|c|c|}
\hline kanban_1 & $\begin{array}{l}\frac{y}{u} \\
\dot{b}\end{array}$ & 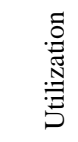 & 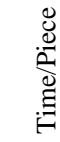 \\
\hline Stock & 25,2 & $52 \%$ & 36,4 \\
\hline WIP & 18,4 & & \\
\hline Finished goods & 6,9 & & \\
\hline 5_Finishing & 5,3 & $46 \%$ & 6,6 \\
\hline 4_Assembly & 4,4 & $36 \%$ & 5,1 \\
\hline 3_Paintwork & 2,3 & $70 \%$ & 9,6 \\
\hline 2_Surface prepareing & 4,4 & $58 \%$ & 8,5 \\
\hline 1_Cutting & 2,0 & $50 \%$ & 6,6 \\
\hline Delivery reliability & & $81 \%$ & \\
\hline
\end{tabular}

Tab. 3. First KANBAN result table

Kanban is a pull system that means the customer orders are already known in advance and are not 
produced on store as it is in push system but they are made to order.After harmonization of orders has been determine the required number of Kanban containers for the products and a next production was simulated, but with new parameters. The results are shown in Tab. 4. From the data it spit out that the stock fell from $25.2 \mathrm{pcs}$ to 19.7 pcs. Utilization is $45 \%$ and the time needed to produce one product is 33.7 seconds.

\begin{tabular}{|c|c|c|c|}
\hline kanban_2 & $\begin{array}{l}\text { U. } \\
\text { ds }\end{array}$ & 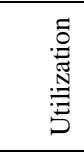 & 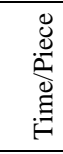 \\
\hline Stock & 19,7 & $45 \%$ & 33,7 \\
\hline WIP & 10,6 & & \\
\hline Finished goods & 9,1 & & \\
\hline 5_Finishing & 3,6 & $47 \%$ & 6,9 \\
\hline 4_Assembly & 1,4 & $40 \%$ & 5,9 \\
\hline 3_Paintwork & 1,7 & $54 \%$ & 8,1 \\
\hline 2_Surface prepareing & 1,9 & $49 \%$ & 7,4 \\
\hline 1_Cutting & 2,0 & $35 \%$ & 5,4 \\
\hline Delivery reliability & & $100 \%$ & \\
\hline
\end{tabular}

Tab. 4. Second KANBAN result table

As a final planning system we used CONWIP. Which settings also consists of two basic parameters: WIP Limit: stock per line and Anticipation horizon: the period per line. In our case, we did not take into account the anticipation horizon, but only the WIP limit. Production results are shown in Tab. 5. From the data it spit out that the stock is 15.3 pcs, utilization is $47 \%$ and the time required to produce one product is 33 seconds. We must not forget also on ability to fulfill orders the in this case it is at $100 \%$ success rate. Of all the rounds of production in which we simulate planning systems, has nothing changed in the processes, only the method of planning.

\begin{tabular}{|c|c|c|c|}
\hline conwip_1 & $\begin{array}{l}\ddot{\ddot{c}} \\
\dot{d}\end{array}$ & 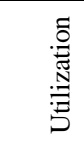 & 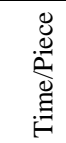 \\
\hline Stock & 15,3 & $47 \%$ & 33,0 \\
\hline WIP & 7,8 & & \\
\hline Finished goods & 7,6 & & \\
\hline 5_Finishing & 2,0 & $48 \%$ & 6,9 \\
\hline 4_Assembly & 1,4 & $38 \%$ & 5,2 \\
\hline 3_Paintwork & 1,3 & $47 \%$ & 6,6 \\
\hline 2_Surface prepareing & 1,9 & $52 \%$ & 7,5 \\
\hline 1_Cutting & 1,3 & $49 \%$ & 6,8 \\
\hline Delivery reliability & & $100 \%$ & \\
\hline
\end{tabular}

Tab. 5. CONWIP result table

\section{FUTURE USING IN REAL PRODUCTION}

Future using of CONWIP planning system in medium sized companies can by very helful to plan and control they production with staying at low stock values, more efficient work, optimization of process and with low costs. Give the customer best kvality for best price. In the future is preparing a concrete example of using MRP push system with a hybrid CONWIP system in a medium-sized company which is engaged in the processing of plastics. Using push system to produce in to the buffer and using CONWIP system to produce from buffer via assembly and packing process to final product store. The whole MRP and CONWIP system is shown in Fig. 5.

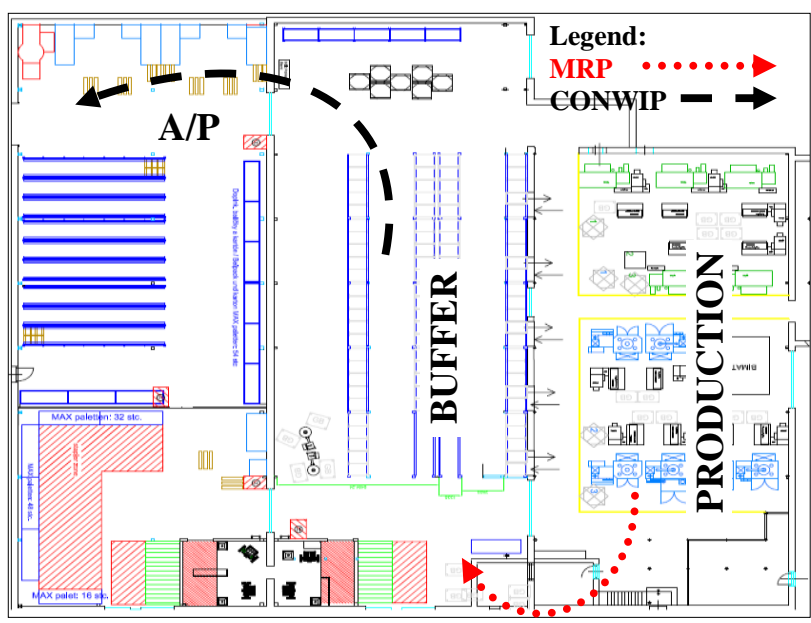

Fig. 5. MRP and CONWIP system in example company, A/P Assembly and Packing

\section{CONCLUSION}

Medium size industries have a challenge to manufacture products at economical prices. They need to embrace management principles surrounding production processes, and planning systems which are effective for the products manufactured by them. An upfront planning and study of the critical factors of the manufacturing processes help them identify areas of risk so that necessary planning and control procedures are put in place. This will eventually help the medium size entrepreneur to eliminate the wastages and increase the production, productivity and profits.

\section{REFERENCES}

[1] Ajorlou, S.; Shams, I. \& Aryanezhad, M. G. (2011). Optimization of a Multiproduct CONWIP-based Manufacturing System using Artificial Bee Colony Approach. In: Proceedings of the International MultiConference of Engineers and Computer Scientists 2011 Vol II, IMECS 2011, March 16-18,2011, Hong Kong. ISSN 2078-0966, ISBN 978-988-19251-2-1

[2] Gregor, M. \& Košturiak, J. (1994). Just-in-Time : Production philosophy for good management. Bratislava : Vydavatel'stvo Elita, 1994. ISBN 80-85323-64-8, $299 \mathrm{~s}$.

[3] http://www.ipaslovakia.sk, (2006). Chromjaková Felicita. Push and pull system of production control. Accessed on: 2012-6-15

[4] Jodlbauer, H. (2008). Production optimization: Value-creating and customer-oriented planning and control. Springer; Wien. ISBN 978-3-211-72752-2

[5] Koblasa, F. \& Manlig, F. (2009). Job shop scheduling problem with multi-shift work system. ACC Journal, 1/2009, s. 15-23, TU v Liberci, ISSN 1803-9782

[6] Manlig, F. \& Gottwaldová, A. (2006). The experience of simulation games in teaching. In: Strojírenská technologie. č.4, r. XI, 2006. s. 28..31 ISSN 1211-4162

[7] McKay, N. K.; Black, W. G. (2007) The evolution of a production planning system: A 10-year case study. In: Computers in Industry 58(8-9): 756-771

[8] R.L. Laforge, C.W. Craighead, Computer-based scheduling in manufacturing firms: some indicators of successful practice, In: Production and Inventory Management Journal 41 (1) (2000) 3 24 